\title{
AS IMPLICAÇÕES DA POLÍTICA DA TERCEIRA VIA PARA A EDUCAÇÃO
}

\author{
Elaine Gomes Ferro ${ }^{1}$, Jorge Luís Mazzeo Mariano ${ }^{2}$ \\ ${ }^{1}$ Mestrado em Educação - UNESP - Presidente Prudente/SP. ${ }^{2}$ Doutorado em Educação - Programa de Pós-Graduação \\ em Educação - UNESP - Presidente Prudente/SP. E-mail: elainegferro@uol.com.br
}

\section{RESUMO}

Este artigo tem como objetivo refletir acerca do processo histórico da educação brasileira - mais especificamente a partir da última década do século XX - com ênfase nas políticas educacionais. As discussões a seguir seguem o debate promovido na coletânea organizada por Lúcia Maria Wanderley Neves, cujo conteúdo se baseia na análise das atuais estratégias do capital para educar o consenso por meio da denominada pedagogia da hegemonia. Segundo Neves (2005) o cenário mostra que há uma busca pela repolitização da sociedade civil, direcionada pela burguesia e que, nesse contexto a escola possui um papel fundamental "na conformação do novo homem coletivo requerido pelo neoliberalismo da Terceira Via". Sendo assim, diante da urgência de superar a visão de consenso criada pelo capitalismo, Mészáros propõe um novo modelo educativo no qual se valorize a ação coletiva na busca da efetivação dos direitos sociais universais e não de indivíduos isolados.

Palavras-chave: Capitalismo; neoliberalismo; Terceira via; educação; contra-hegemonia.

\section{INTRODUÇÃO E OBJETIVO}

O presente artigo foi elaborado com o objetivo de refletir a respeito do processo histórico da educação brasileira - mais especificamente a partir da última década do século XX - com ênfase nas políticas educacionais.

$\mathrm{Na}$ história recente da educação é possível notar que as políticas educacionais privilegiaram certos setores sociais da elite negligenciando, em contrapartida, a qualidade de ensino para as camadas populares. Partindo desse pressuposto, buscamos entender como a área educacional tem sido apropriada pela política da Terceira Via para atender à estratégia do capital para a formação do consenso.

Ao final, esse artigo apresenta reflexões que visam colaborar para o debate acerca da superação dos modelos educativos implantados no país sob a égide do capitalismo.

\section{METODOLOGIA}

Essa pesquisa utiliza uma abordagem qualitativa através de uma pesquisa teórica. As discussões a seguir seguem o debate promovido na coletânea organizada por Lúcia Maria 
Wanderley $\mathrm{Neves}^{1}$, cujo conteúdo se baseia na análise das atuais estratégias do capital para educar o consenso por meio da denominada pedagogia da hegemonia. Quanto à forma, optou-se por apresentar uma síntese temática cujo enfoque se direciona para a análise das principais políticas empreendidas no campo educacional relacionando com o plano político geral a partir da primeira década de 1990.

\section{RESULTADOS}

Nesse tópico, o olhar se direcionará para as políticas educacionais a partir da adoção do modelo politico denominado Terceira $\mathrm{Via}^{2}$, por isso será importante dar um salto histórico, tendo em vista que a implantação dessa política se inicia na década de 1990. A Terceira Via surge no cenário político:

[...] como alternativa aos efeitos negativos do capitalismo e das insuficiências da social-democracia europeia, esse programa procura apresentar uma nova agenda político-econômica para o mundo nos limites do capitalismo constituindo-se em importante instrumento de ação da nova pedagogia da hegemonia. [...] tem como objetivo a reforma ou governo do capitalismo por intermédio das mudanças na politica e na economia. (LIMA; MARTINS, p.43-44, 2005)

A politica da Terceira Via, traz em seu discurso, criticas ao neoliberalismo, sobretudo no que diz respeito ao "Estado Mínimo" e o "individualismo econômico". Como destaca Lima e Martins (2005), a preocupação dessa política não se relaciona com a precariedade atual observada no mundo do trabalho, pois interessa muito mais a estabilidade política e social das nações.

Em sua carta de intenções, a política de Terceira Via defende a naturalização do sistema capitalista, ou seja, esse deve ser concebido como a-histórico, não cabendo aos homens tomar a direção do processo histórico. A participação da sociedade civil é essencial e sua postura deve ser expressa na prestação de serviços e não na reivindicação dos direitos coletivos. Com relação ao Estado, esse deve passar por uma reforma abarcando alguns aspectos como: “[...] descentralização administrativa, democratização, transparência, eficiência administrativa, espaços de participação e a função reguladora dos riscos, sociais, econômicos e ambientais." (LIMA; MARTINS, p.51, 2005).

Outra proposta da Terceira Via é a governabilidade articulada com dois eixos, ou seja, entre a esfera pública e privada e nos âmbitos nacional e internacional. Em última instância essa política

\footnotetext{
${ }^{1}$ A referida coletânea se encontra publicada em formato de livro com o título: A Nova Pedagogia da Hegemonia: Estratégias do Capital para Educar o Consenso. As análises presentes na obra utilizam o referencial teórico gramsciano.

${ }^{2}$ Destaca-se que o conceito Terceira Via foi sistematizado pelo sociólogo britânico Antony Giddens. 
tende a refletir que "[...] o capitalismo não sobrevive sem o Estado, [...] e o Estado deve estar a favor do capitalismo." (LIMA; MARTINS, p.51, 2005).

Os autores Lima e Martins (2005), enfatizam que as estratégias que a Terceira Via toma para si, refletem o desejo de preservar os princípios do liberalismo como: permitir que o Estado fique imune aos conflitos de classe, enxergar a economia através da ótica do livre mercado, bem como a naturalizar das desigualdades sociais.

A articulação politica da Terceira Via, busca "reinventar" a sociedade civil conferindo-Ihe o caráter de "ativa". Essa nova sociedade civil se basearia na ajuda mútua, inspirada na ideia de filantropia e suas atribuições nesse novo contexto social seriam:

[...] de proteção da esfera pública estatal; de prevenção de crimes pelo incentivo da ação comunitária; do estimulo à família democrática; do incentivo ao envolvimento cívico de indivíduos e grupos sociais, articulando liberdade individual com solidariedade e responsabilidade social para a criação de um sistema moral capaz de garantir o pleno exercício da "cidadania renovada" e da harmonização social por meio de um pacto para a promoção do bem comum. (LIMA; MARTINS, p.53, 2005)

No Brasil, o projeto de implantação da política de Terceira Via se deu em dois momentos. Neves (2005) destaca, que o primeiro momento tem início na primeira metade dos anos de 1990 e vai até a elaboração do Plano Real. A partir desse período se observou no Brasil algumas políticas que vão em direção às propostas desse novo projeto de sociabilidade como: a abertura do mercado nacional, a precarização das políticas sociais públicas que refletiam o modelo de Estado de bem-estar social, a intensa estimulação a privatização, o aumento de "novos movimentos sociais" com destaque para as organizações não governamentais entre outras medidas.

Essas alterações no contexto político e econômico se refletiram no campo educacional que passou por:

[...] um momento de difusão da ideologia da qualidade total, da ideologia da qualidade total, da transformação dos dirigentes em gestores educacionais, do começo do sucateamento da educação superior pública e da transformação do Conselho Nacional de Secretários de Educação (Consed), de órgão contestador das politicas oficiais, nos anos finais da ditadura militar e nos anos de abertura politica, em instrumento difusor das politicas neoliberais para a educação básica. (NEVES, p. 92, 2005)

As transformações no setor político e social ocorridas nesse primeiro momento, tiveram continuidade no segundo momento de implantação do projeto político de orientação da Terceira Via com os dois governos de Fernando Henrique Cardoso. Nos governos de FHC essa orientação 
política se faz presente nos seus esforços em reestruturar o Estado em suas funções, passando de produtor de bens e serviços à articulador de iniciativas privadas.

Há ainda um esforço do Estado em promover parcerias com a sociedade civil. Um exemplo dessa aproximação estatal com a sociedade é a criação do Programa Comunidade Solidária, que tinha como um de seus principais objetivos a tentativa de amenizar a situação de pobreza extrema estabelecendo parcerias com organizações ligadas à sociedade civil.

Para Neves (2005), esse segundo momento buscava fortalecer a sociedade civil pela divulgação da participação da população em atividades coletivas baseadas na solidariedade e no compromisso social. Nesse contexto, de acordo com a referida autora, há uma mudança na ação do associativismo que de reivindicador de direitos passa a prestador de serviços de "interesse público".

No governo seguinte, ou seja, com a chegada de Lula da Silva à presidência da República em 2003, verifica-se um terceiro momento de expansão de consolidação do projeto neoliberal da Terceira Via. Neves (2005) ainda indica que através do slogan "Brasil um pais de todos", o governo Lula buscou a inclusão mínima das massas excluídas através de projetos sociais, como o programa Fome Zero ${ }^{3}$ que substitui o então programa Comunidade Solidária gestado no governo antecessor.

Com essa nova configuração a sociedade civil acaba perdendo de vista seu potencial transformador e contestador das políticas estatais de caráter autoritário, repressivo e burocrático. Segundo Neves (2005), o cenário mostra que há uma busca pela repolitização da sociedade civil, direcionada pela burguesia.

A escola no contexto apontado tem um papel fundamental "na conformação do novo homem coletivo requerido pelo neoliberalismo da Terceira Via." (NEVES, p.104, 2005). Desse modo, verifica-se intensas reformas na escola pública brasileira com as seguintes finalidades:

[...] formar, no espaço nacional, intelectuais urbanos de novo tipo, ou seja, especialistas e dirigentes que do ponto de vista técnico, possam aumentar a competitividade e produtividade do capital, nos marcos de um capitalismo periférico e do ponto de vista ético politico, possam criar e difundir uma nova cidadania politica, baseada na colaboração de classes [...]. (NEVES, p.104, 2005)

A introdução dos temas transversais, com a reforma curricular da educação básica implantada por FHC a qual teve continuidade no governo Lula, tem por objetivo a formação éticopolitica do intelectual urbano de novo tipo. (NEVES, 2005).

\footnotetext{
${ }^{3}$ De acordo com Neves (2005) o Programa Fome Zero visava possibilitar a todos os brasileiros o recebimento adequado de alimentos com regularidade e qualidade, através da colaboração de todos os setores do governo e da sociedade civil organizada. 
No ensino superior as reformas empreendidas pelo modelo neoliberal de Terceira Via, tem colaborado para a sua fragmentação, privatização e empresariamento, através de reformas que visam a formação de uma subjetividade de orientação neoliberal.

A reforma da educação superior [...], submete a produção do conhecimento nacional a diretrizes de organismos internacionais, reforça a ideia neoliberal do público não estatal, estimulando jurídica e financeiramente o empresariamento da educação superior, ao mesmo tempo em que legitima a submissão da escola à empresa, o dualismo entre instituições de ensino, utiliza-se o acesso à educação superior como instrumento compensatório ao histórico apartheid social brasileiro, além de agudizar a precarização das relações trabalhistas. (NEVES, p.106, 2005)

Além da educação, outros setores se tornam importantes parceiros na promoção da ideologia do consenso. Desse modo, a mídia, a igreja e as ONGs, cumprem um papel importante na divulgação e formação dos valores de responsabilidade social. Por reproduzirem direta ou indiretamente a visão de mundo burguesa, esses órgãos se apresentam como aparelhos privados de hegemonia.

Segundo Martins (2005), a classe empresarial, por sua vez, também aparece como importante articulador das políticas de Terceira Via. Através da "responsabilidade social empresarial", esse grupo tem apostado cada vez mais no investimento de projetos de caráter social, principalmente no campo da educação.

Dentro desse cenário apontado pelos autores, percebe-se que a burguesia tem cada vez mais investido em educação para efetivar e consolidar seu plano neoliberal. O papel do Estado nesse contexto é o de concretizar a educação com vistas a obtenção do consenso, através do estabelecimento de uma nova relação com a sociedade civil, essa última, por sua vez, passa a ser responsável pelo bem-estar social dos indivíduos e dos grupos, desresponsabilizando o Estado desse compromisso "pouco rentável".

\section{DISCUSSÃO}

Tendo em vista a colocação dos autores se percebe a urgência de um novo paradigma educativo que, além da superação da visão de consenso, direcione-se aos indivíduos sociais e não aos indivíduos isolados.

Esse novo paradigma educacional pode ser pensado a partir das reflexões estabelecidas por István Mészáros na obra intitulada "A Educação para Além do Capital", em que apresenta subsídios para se pensar um mote educativo que rompe com a lógica capitalista. Esse rompimento 
se faz necessário, antes de tudo, pois o compromisso histórico do capitalismo é a exploração mercadológica:

Quanto mais "avançada" a sociedade capitalista, mais unilateralmente centrada na produção de riqueza reificada como fim em si mesma e na exploração das instituições educacionais em todos os níveis, desde as escolas preparatórias até as universidades - também na forma de "privatização" promovida com suposto zelo ideológico pelo Estado - para a perpetuação da sociedade de mercadorias. (MÉSZÁROS, p. 80, 2008)

Para esse mesmo autor uma educação alternativa a esse modelo dever ser comprometida com a transformação social. A educação de caráter hegemônico colabora com a dominação ideológica permanente na vida dos indivíduos, embora esses indivíduos não consigam em certos momentos reconhecer a influência dessa dominação. Ou seja, a educação de caráter hegemônico visa encobrir as desigualdades sociais e ao mesmo tempo busca a conformação e o consenso para a manutenção da sociedade capitalista. Enquanto que uma educação de caráter contra hegemônico busca desvelar essa sociedade com o objetivo de transformá-la, buscando a superação de suas desigualdades.

A individualidade é um aspecto valorizado na educação do homem no contexto capitalista, haja vista que essa tende a fragmentar a luta social. Em oposição à esse individualismo capitalista, Mészáros propõe um novo modelo educativo no qual se valorize a ação coletiva na busca da efetivação dos direitos sociais universais e não de indivíduos isolados. Nesse novo modelo a educação não deve ser considerada como "um período estritamente limitado da vida dos indivíduos, mas como desenvolvimento contínuo da consciência socialista na sociedade como um todo [...]" (MÉSZÁROS, p. 80, 2008).

Enfim, o grande compromisso desse modelo é o de transformação radical e consciente da educação com vistas a desmistificar a ideologia capitalista e superar o consenso que a mantem.

\section{CONCLUSÃO}

A história denota que a educação tem sido utilizada no Brasil como uma importante ferramenta das classes hegemônicas para consolidação das políticas de ordem capitalista.

O processo histórico apresentado evidencia que as reformas e políticas dirigidas à educação não estão desconectadas do contexto sócio politico de sua implantação. Aliás, refletem diretamente o interesse da classe que detém o poder politico e econômico, fazendo parte de um projeto societário amplo cuja educação é um dos aspectos a colaborar com a sua efetivação. 
Boa parte das publicações dentro da área da educação busca avaliar o impacto das politicas públicas educacionais em si mesmas, desconsiderando o contexto histórico, politico e ideológico que antecede a sua formulação e implantação. Uma análise dessa natureza se torna vazia e aligeirada e colabora mais para a manutenção e conformação da ideologia hegemônica do que para a sua superação.

Nesse sentido, é possível observar que o referencial teórico visitado se mostra consistente e em certo sentido colabora para o desvelamento da realidade encoberta pela ideologia hegemônica. Por fim, a apresentação do modelo educativo proposto por Mészáros se apresenta como uma alternativa contra hegemônica válida para a mudança radical da sociedade.

\section{REFERÊNCIAS}

LIMA, K. R. de S; MARTINS, A. S. Pressupostos, princípios e estratégias. In: NEVES, Lúcia Maria Wanderley (Org.). A nova pedagogia da hegemonia: estratégias do capital para educar o consenso. São Paulo: Xamã, 2005.

MARTINS, A. S. Estratégia burguesa de obtenção do consenso nos anos de neoliberalismo da Terceira Via. In: NEVES, Lúcia Maria Wanderley (Org.). A nova pedagogia da hegemonia: estratégias do capital para educar o consenso. São Paulo: Xamã, 2005.

MÉSZÁROS, I. A educação para além do capital. Isa Tavares (Trad.). 2. Ed. São Paulo: Boitempo, 2008.

NEVES, L. M. W. A sociedade Civil como espaço estratégico de difusão da nova pedagogia da hegemonia. In: NEVES, Lúcia Maria Wanderley (Org.). A nova pedagogia da hegemonia: estratégias do capital para educar o consenso. São Paulo: Xamã, 2005. 